\title{
OS CONHECIMENTOS PRÉVIOS SOBRE SER VIVO/CÉLULA DOS ESTUDANTES INGRESSOS NO CURSO DE ENGENHARIA DE PESCA
}

\author{
Darcy Ribeiro de Castro* \\ Jacqueline de Araújo Guerra** \\ Keisyara Bonfim dos Santos*** \\ Nadijara Pereira dos Santos ${ }^{* * *}$ \\ Samara Rocha Mendes dos Santos**** \\ Taliany Santos de Amorim******
}

RESUMO: Este trabalho trata da formação de conceitos científicos no Ensino Superior do Curso de Engenharia de Pesca da Universidade do Estado da Bahia (UNEB), Campus XXIV, XiqueXique-BA, a partir dos conhecimentos prévios dos alunos. Envolve uma turma com 43 estudantes ingressos no primeiro semestre de 2013, na faixa etária de 17 a 30 anos. Este estudo tem como base as concepções espontâneas e científicas de estudantes sobre célula/ser vivo. Objetivamos identificar os conhecimentos dos alunos nessa área e usamos para tal a entrevista estruturada (questionário). Os dados foram analisados de acordo com o método comparativo e os referenciais apresentados. Observamos que os estudantes, em geral, apresentaram um conhecimento científico limitado, tanto para os conceitos biológicos centrais quanto para os derivados.

Palavras-chave: Conhecimento prévio célula/ser vivo. Vygotsky. Formação. Ensino Superior.

CONOCIMIENTOS PREVIOS ACERCA DEL SER VIVO/CÉLULA DE LOS ESTUDIANTES INGRESOS EN EL CURSO DE INGENIERÍA PESQUERA

RESUMEN: Este trabajo trata de la formación de conceptos científicos en la Educación Superior del curso de Ingeniería Pesquera de la Universidad del Estado de Bahia (UNEB), Campus XXIV - XiqueXique-BA, a partir de los conocimientos previos de los estudiantes. Implica una clase de 43 estudiantes ingresos en el primer semestre de 2013, de 17 a 30 años de edad. Este estudio tiene como base las concepciones espontáneas y científicas de estudiantes acerca célula/ ser vivos. Tenemos como objetivo identificar los conocimientos de los alumnos acerca el tema y usamos para tal la entrevista estructurada (cuestionario). Los datos fueron analizados con el método comparativo y los referenciales presentados. Observamos que los estudiantes, en general, presentaron un conocimiento científico limitado, tanto para los conceptos biológicos centrales cuando para los derivados.
*Universidade do Estado da Bahia (UNEB), Campus XXIV, Xique-Xique, Bahia, Brasil. Doutor em Ensino, Filosofia e História das Ciências - Universidade Federal da Bahia/Universidade Estadual de Feira de Santana-UFBA/ UEFS. Membro do Núcleo de Estudo e Pesquisa Ambiental-NEPEA. E-mail: dcastro@uneb.br

* * Universidade do Estado da Bahia (UNEB), Campus XXIV, Xique-Xique,

Bahia, Brasil. Graduanda em Engenharia de Pesca. Bolsista do Programa de Iniciação Científica - PICIN/UNEB. E-mail: araujoguerrajacqueline@gmail.com

* * Universidade do Estado da Bahia (UNEB), Campus XXIV, Xique-Xique,

Bahia, Brasil. Graduanda em Engenharia de Pesca.Bolsista do Programa de Iniciacão Científica - Fundação do Amparo à Pesquisa do Estado da Bahia (FAPESB). Membro do Núcleo de Estudo e Pesquisa Ambiental (NEPEA).

E-mail: keisyara_santos@hotmail.com

*** GUniversidade do Estado da Bahia (UNEB), Campus XXIV, Xique-Xique, Bahia, Brasil. Graduanda em Engenharia de Pesca. Bolsista Voluntária do Núcleo de Ensino e Pesquisa Ambiental (NEPEA) UNEB). Membro do Núcleo de Estudo e Pesquisa Ambiental (NEPEA).

E-mail: nadjara_pereira@hotmail.com

* * * * Universidade do Estado da Bahia (UNEB), Campus XXIV, Xique-Xique, Bahia, Brasil. Graduanda em Engenharia de Pesca. Bolsista Voluntária do Núcleo de Ensino e Pesquisa Ambiental (NEPEA UNEB). Membro do Núcleo de Estudo e Pesquisa Ambiental (NEPEA). E-mail: samara_quixabeira2011@hotmail.com

****** Universidade do Estado da Bahia (UNEB), Campus XXIV, Xique-Xique, Bahia Brasil. Graduanda em Engenharia de Pesca. Bolsista do Programa de Iniciação Científica - PICIN/UNEB. Membro do Núcleo de Estudo e Pesquisa Ambiental (NEPEA). E-mail: talianysantosdeamorim@yahoo.com.br 
Palabras clave: Conocimiento previo célula/ser vivo. Vygostki. Formación. Educación Superior.

\section{FISHING ENGINEERING ENTERING STUDENT'S PREVIOUS KNOWLEDGE ABOUT LIVING BEINGS/CELL}

ABSTRACT: This work deals with the formation of scientific concepts in High Education in the Fishing Engineering course at the State University of Bahia (UNEB), Campus XXIV-Xique-Xique- BA, from students' previous knowledge. It envolves a class with 43 students' starting in 2013's first semester, aged 17 to 30 years. This study is based on student's spontaneous and scientific conceptions about cell/living beings. We aimed to identify students' knowledge in this area and use structured interview (questionnaire). Data was analyzed according to the dialectical method and references presented. We observe that, in general, students presented a limited scientific knowledge for both central and derivative biological concepts.

Keywords: Previous knowledge cell/living beings. Vygotsky. Formation. Higher education. 


\section{INTRODUĈ̣̃O}

Este trabalho trata da formação de conceitos científicos no Ensino Superior, a partir dos conhecimentos prévios dos alunos, com base nas fases do desenvolvimento estudadas por Vygotsky (1991, 2010). Consideramos para tal a fase de pensamento abstrato que persiste no ser humano a partir da adolescência. Entendemos que esse estágio poderá não ter sido bem-definido na escolaridade anterior à graduação por conta das dificuldades inerentes ao ensino-aprendizagem nos Ensinos Fundamental e Médio: falta de professores habilitados na área, de reconhecimento escolar da importância do trabalho prático e das instalações físicas laboratoriais, dentre outras.

Este estudo, apoiado na perspectiva da Teoria Histórico-Cultural de Vygotsky sobre a construção dos conceitos científicos, possibilitará formular uma melhor compreensão sobre as formas de concepção dos alunos(as) com respeito aos conteúdos de estrutura e funcionalidade de ser vivo/célula e a descrição que eles fazem para compreendê-los. A Teoria Histórico-Cultural consta de conceitos fundamentais para a realização deste trabalho, tais como desenvolvimento humano, conhecimento espontâneo/científico e zona de desenvolvimento. Essa abordagem poderá ser usada como referência para se analisar o conhecimento biológico dos alunos ingressos no Curso de Engenharia de Pesca, da Universidade do Estado da Bahia-UNEB, Campus XXIV.

Para isso, é fundamental investigar o que os estudantes universitários sabem sobre a estrutura e a funcionalidade de ser vivo/célula, tendo em vista os problemas na escolaridade anterior e que se perpetuam na graduação, como mencionado anteriormente. Para isso, inicialmente objetivamos identificar os conhecimentos prévios dos alunos sobre os conceitos biológicos relacionados aos seres vivos (estrutura celular, grupos, tamanho, ciclo de vida e funções vitais). A partir deles, procuraremos conhecer melhor as dificuldades e as potencialidades de compreensão dos alunos (pontos fracos e fortes) em relação à estrutura e à funcionalidade de ser vivo/célula, com vistas a contribuir com a formação deles na sequência do curso, com base no trabalho relacionado com as disciplinas correlatas.

\section{A FORMACִ̃̃O DE CONCEITOS CIENTÍFICOS E O CONHECIMENTO BIOLÓGICO DOS. ESTUDANTES SOBRE SER VIVO/CÉLULA}

Os estudos de Vygotsky contemplam três fases do desenvolvimento humano como parte da infância ( 0 a 11 anos de idade) e da adolescência (12 a 20 anos de idade): o pensamento sincrético ${ }^{1}$, o pensamento por complexo (criança em fase pré-escolar) e o pensamento conceitual (criança/adolescente em fase escolar). Para esse trabalho, por se tratar da formação de conceitos para jovens estudantes e ainda não serem fases estanques ou bem-definidas pela idade, consideramos apenas a fase de pensamento conceitual na sua relação com o pensamento por complexo. 


\title{
As fases de pensamento por complexo e conceitual
}

\begin{abstract}
Num complexo, as crianças e os adolescentes associam os objetos mediante relações concretas e factuais que podem mudar uma ou mais vezes durante o processo de organização do pensamento. Embora tenha associações baseadas em pontos factuais, elas são extremamente subjetivas. Essas características selecionadas podem parecer irrelevantes para os adultos e/ou para o processo de ensino. No limite entre os complexos e os conceitos propriamente ditos, há o estágio de pseudoconceito, no qual a criança/adolescente ou mesmo pessoas adultas generalizam fenotipicamente, mas, psicologicamente, seu conceito é muito diferente do conceito propriamente dito. Essa questão é percebida quando a criança ou o adolescente sabe definir o conceito e não sabe e/ou tem dificuldade de explicá-lo corretamente. Isso pode acontecer, também, com o adulto, conforme assinala Vygotsky (1991, 2010).
\end{abstract}

Para Vygotsky (1991, 2010), na fase de pensamento abstrato, considera-se o grau máximo de semelhança para agrupar os objetos de acordo com seus atributos. Por exemplo, a criança ou o adolescente agrupa objetos redondos e pequenos; vermelhos e achatados, conforme os atributos de cor e forma. Essa fase se diferencia do complexo pela capacidade de síntese e análise que tem o sujeito, o que lhe direciona para a formação de conceito. Podem ser observadas características transitórias quando as crianças/adolescentes têm dificuldades de fazer tais agrupamentos, ou os fazem em relação a determinados atributos (cor e forma), e não conseguem fazer em relação a outros (forma e espessura), ou, ainda, não conseguem conceituar devidamente as coisas novas.

Com base em Vygotsky $(1991,2010)$, a abstração de um traço auxilia na generalização do conceito, a exemplo da forma que pode ser separada no meio de muitos outros caracteres (cor, tamanho, espessura), podendo ser geral e abstrato o processo envolvido, como ocorre com o conceito de cadeira e talher que são formados no cotidiano. Quando se trata do conhecimento científico correlacionado ao espontâneo, em que se precisa abstrair claramente traços específicos em relação ao objeto/fenômeno, como no caso da massa ou do peso da cadeira, do talher, do ser humano etc., é necessário auxiliar o sujeito na elaboração do referido conceito. Para isso, é exigido o desprendimento desse sujeito do objeto/fenômeno, a fim de ampliar o pensamento complexo que comumente faz parte do cotidiano, considerando que mesmo pessoas adultas usam o conhecimento espontâneo para explicar o científico; usam, por exemplo, o conceito de calor para explicar temperatura, e o de massa, para definir o peso. O professor pode contribuir, nesse processo, com a proposição e a aplicação de estímulos externos (aulas práticas) mediante situações-problemas que estimulam a criança/adolescente a inferir significativamente determinados traços que poderão ser canalizados para a formação do conceito científico.

A percepção de traços comuns num objeto/fenômeno facilita a aprendizagem de uma palavra quando esta for incorporada à experiência com o objeto de forma significativa em que se expressa uma ação de pensamento dos sujeitos. O estímulo externo propiciado pelo professor e a condução da tarefa por ele são fundamentais para que os traços sejam percebidos e internalizados por 
esses sujeitos. O conceito formado é o traço comum a ser compartilhado. Assim, os vínculos subjetivos completamente inconscientes, aos poucos, poderão ser substituídos por conexões objetivas, ao passo que se media a relação dos alunos com objeto.

Nesse sentido, a principal função dos complexos é estabelecer elos e relações e dar início
à unificação das impressões desordenadas (fase sincrética); mas, ao organizar elementos
discretos da experiência em grupos, cria uma base para generalizações posteriores e,
portanto, para a formação de um conceito. Para formar um conceito, é preciso abstrair,
isolar elementos e examinar os elementos abstratos separadamente da totalidade da
experiência concreta de que fazem parte (unir e separar), conforme assinala Vygotsky
(1991, 2010). Isso já começa a acontecer nos complexos, pois, se alguém agrupa elementos
por algum(ns) traço(s) comum(ns), é porque os abstraiu; o fato é que os complexos ainda
não alcançaram o nível de desenvolvimento em que o sujeito prescinde de objetos, fatos
ou eventos que o geraram. A abstração, porém, ocorre progressivamente desde o início do
período escolar.

A generalização é iniciada pelas crianças/adolescentes num momento em que elas ainda estão muito presas aos objetos; elas já começam a separar traços, mas ainda não são capazes de analisar devidamente a relação entre os traços de um objeto/fenômeno como resposta para determinado tipo de situação-problema. Como exemplo disso, temos a dificuldade encontrada por alunos em diferentes faixas etárias para agrupar figuras pela forma e a espessura as quais representam um fenômeno/objeto.

Para Vygotsky (1991, 2010), o sujeito em formação leva consigo as características dos estágios de desenvolvimento anterior. A forma e o conteúdo da resposta da criança/ adolescente ao estímulo é que vão evidenciar o seu nível de desenvolvimento psicológico. Quando ela busca organizar dados (ordem e critérios) acerca dos objetos/fenômenos, mas faz uma série de relações objetivas e significativas, está operando com o pensamento complexo; quando separa traços, generaliza e explica (pensamento abstrato) as questões levantadas por elas mesmas ou pelo professor sem a presença do objeto, sinaliza o domínio conceitual. $\mathrm{O}$ fato de as explicações dos sujeitos em formação para proposições apresentarem relações lógicas e abstratas, em vez de conexões factuais e concretas (complexo), significa que já estão operando com o pensamento conceitual.

O domínio conceitual desses sujeitos se desenvolve quando se observa que eles conseguem encontrar nos objetos pistas para responder às suas questões ou conseguem manipulá-los e interagir consigo mesmos, a fim de conseguir suas respostas. Isso possibilita a criação de categorias de respostas (tipo de pensamento, conhecimento e generalização), que podem anunciar os gradativos avanços no pensamento conceitual deles. O uso das frases pelas crianças ou os adolescentes e a decomposição em nível de conceitos expressos pela linguagem oral e/ou escrita podem indicar o nível de pensamento desses sujeitos, se eles usam mais ou menos a explicação espontânea ou científica para o fenômeno analisado.

Vygotsky (2010) afirma que o verdadeiro conhecimento a ser adquirido pelos sujeitos em formação é aquele que se direciona para explicação da causa de 
um evento. Quando isso ocorre, a explicação funcional baseada no egocentrismo diminui. Por essa razão, a atividade prática realizada pelo sujeito pode se aproximar do pensamento realista do meio (objetivo), da lógica e da racionalidade que se fundamentam no materialismo histórico social. Por outro lado, se o sujeito não conhece o que está por trás de um determinado fato ou problema, é porque a compreensão funcional espontânea ou egocêntrica para o mundo é dominante em relação ao pensamento causal. A ação executada por esta é vinculada ao pensamento subjetivo inerente ao ser biológico humano, sendo esta uma posição idealista do mundo mais próxima da lógica do sonho e do devaneio.

Com base em Vygotsky (1991, 2010), uma maneira eficiente para auxiliar na compreensão dos conteúdos e das formas de conhecimento dos alunos é a identificação de seus conceitos na Zona de Desenvolvimento Real (ZDR) para que possa contribuir com o desenvolvimento de aulas, atendendo à Zona de Desenvolvimento Proximal (ZDP) deles, também chamada de Zona de Desenvolvimento Imediato (ZDI). É valorizada, nessa perspectiva, a relação entre o que o aluno sabe e pode realizar com auxílio do professor para chegar a um novo patamar de conhecimento ou Zona de Desenvolvimento Real (ZDR).

Para este trabalho, é importante a diferenciação entre o conhecimento espontâneo e os conhecimentos científicos, como parte do desenvolvimento conceitual do ser humano. Vygotsky (2000) afirma que os conceitos espontâneos estão ligados à experiência de vida, são assistemáticos, empíricos e de uso não intencional, têm fraca generalização, são usados do particular para o geral, são base para introdução do conceito científico, não são conscientes e são orientados para o objeto representado, e não para o ato de pensar. Os conceitos científicos são aprendidos sistematicamente, mediante operações lógicas e abstratas, apresentam boa generalização, estão relacionados à experiência transmitida intencionalmente, são usados do geral para o particular, são base para a consciência, a generalização e para a sistematização dos conceitos espontâneos.

\section{Corpo do conhecimento biológico dos estudantes sobre ser vivo/célula}

A pesquisa sobre estrutura e funcionalidade de ser vivo/célula enfatiza, nas suas várias fases, os conteúdos e as formas de conhecimento dos alunos evidenciados nas tarefas planejadas e desenvolvidas pelos professores do Curso de Engenharia de Pesca. Os alunos mais velhos tendem a apresentar um desenvolvimento conceitual mais avançado em relação aos mais novos por conta das vivências sociais e escolares que contribuíram para a sua aprendizagem. Entretanto, ao considerar os alunos mais velhos submetidos a vários contextos (realização de tarefas escolares e uso do conceito para responder a questões novas) e maior escolaridade, as dificuldades de assimilação dos conteúdos podem ser comuns, mesmo no Ensino Superior (CASTRO, 2010).

Nesse sentido, é evidente a falta de pré-requisitos para estudante ingresso na universidade porque houve falha na sua formação básica nos conteúdos, a saber: organismo-célula, estrutura de seres vivos, nutrição-corpo e ambiente, obtenção e reserva de nutrientes etc. Para evitar essa dificuldade, destacamos a importância de, desde cedo, proporcionar a eles noções simples sobre os conceitos, 
tais como: vida, ser vivo, respiração celular, nutrição e crescimento (CASTRO, 2010). Se a escola básica não o faz, na universidade é possível dar um passo atrás no ensino e planejar um ensino que seja voltado para as necessidades dos alunos, se assim estes tiverem motivados para superar suas limitações. Entretanto, não desconsideramos os conteúdos assimilados pelos estudantes adquiridos nos Ensinos Fundamental e Médio, porque refletem os aprendizados trazidos por eles do seu meio, influenciados pelos fatores econômicos, políticos e sociais, que, por sua vez, podem limitar ou favorecer um melhor ensino do professor em sala de aula. Ademais, destacamos que o conhecimento atual dos alunos está vinculado à concepção dos professores, geralmente voltada para a formação geral deles, com reflexo na sua adaptação à sociedade ou para a sua profissionalização (SAVIANI, 2005), mas que não consideravam os seus conhecimentos prévios como ponto de partida para o ensino.

A questão central dessa discussão é averiguar se conhecimentos espontâneos para as temáticas supracitadas encontrarão correspondência com os conceitos científicos na universidade, uma vez que são conteúdos que naturalmente guardam alguma relação entre o pessoal, a experiência e os fenômenos biológicos (CASTRO, 2010). Uma possível resposta para essa questão, bem como para outras perguntas levantadas neste texto, poderá ser encontrada mediante a compreensão dos conceitos em rede, em que um conceito central poderá derivar muitos outros conceitos, conforme a orientação de Vygotsky $(1991,2010)$ e Castro (2014) acerca da formação conceitual.

Nesse sentido, podemos citar os trabalhos de Moura (2000) em relação aos conceitos de seres vivos em curso de formação com jovens e adultos, assim como as pesquisas realizadas por Caballer e Giménez (1993) e Shaefer (1979) sobre o conceito central da função vital "crescimento de seres vivos", tendo em vista a biologia celular. Por outro lado, devemos assinalar que autores como Jiménez-Aleixandre e Díaz-Bustamante (1993), Zamora, Silva e Guerra (1993), Bahar, Johnstone e Hansell (1999), Tekka Ya, Özkan e Sungur (2001), Yorek, Sahin e Aydin (2009) e Yorek, Sahin e Ugulu (2010) relatam as dificuldades de aprendizagem que os estudantes têm em relação aos referidos conceitos biológicos e sua derivação.

Com base em Shaefer (1979) e Castro (2010), alguns conceitos/termos de biologia são centrais, pois funcionam como núcleo por meio do qual outros conceitos podem estar associados ou serem formados (derivados). Como exemplo dos primeiros, temos vida, ser vivo, crescimento, reprodução, solo, vegetal, alimento, sangue...; quanto ao segundo, citamos célula, divisão celular, nutrientes, gametas, respiração celular, hemoglobina etc. Para o primeiro autor, o conhecimento dos alunos sobre o conceito de crescimento de plantas aumenta com escolaridade, enquanto diminui para o crescimento de animais. Ele associa tal questão à maior importância que é dada aos conteúdos de plantas em relação ao de animais nas aulas desse nível de ensino. Inferimos que a associação que eles fazem entre os fenômenos/objetos e os conceitos centrais/primitivos é fundamental para elaboração de conceitos derivados. Podemos admitir, pela razão exposta, que a formação desses conceitos de animais em relação às plantas é reduzida. 
Discordando da visão defendida por Shaefer (1979), autores como Yorek, Sahin e Ugulu (2010) informam que os conteúdos de células animais aparecem mais nos livros didáticos da escola básica, por isso, eles representam (desenhos) mais essas células $(75 \%)$ do que as células vegetais (25\%), incluindo a forma redonda $(48,7 \%)$, a retangular $(36,3 \%)$ e outras $(15 \%)$. Há uma representação que traz diferenças enormes entre os alunos dos Ensinos Fundamental e Médio em relação aos componentes da célula, mas, no que se refere aos dados escritos, percebemos uma diferenciação pouco expressiva. Isso indica que os alunos expressam melhor seus conhecimentos através do desenho do que na escrita, já que essa última forma de linguagem parece estar mais relacionada com o desenvolvimento da linguagem oral propiciado, principalmente, pelo ensino escolar (CASTRO, 2014).

Yorek, Sahin e Ugulu (2010) afirmam que, por exemplo, 75\% dos estudantes do Ensino Médio reconhecem a célula como unidade básica da vida e do ser humano/corpo humano, mas muitos deles podem não ter a compreensão básica de como suas estruturas interagem para exercer as suas funções e como isso se relaciona com a estruturação e o funcionamento do ser vivo. Para eles, os avanços na compreensão dos estudantes acerca da integração funcional do ser vivo devem começar desde cedo com células, estruturas químicas e celulares (organelas), para que eles avancem na escolaridade posterior com os conceitos na área, sendo que, para isso, entendemos que a escola precisa iniciar um bom ensino de conceitos primitivos. Para esses autores, a derivação conceitual é maior para os conceitos de animais em relação ao conceito de plantas.

Para Zamora, Silva e Guerra (1993), a dificuldade dos alunos na assimilação dos conteúdos de célula e suas funções deriva da concepção que eles têm sobre a célula como entidade isolada, a qual não funciona em miniatura como um organismo multicelulado, muito menos exerce uma atividade interativa dentro de um sistema complexo. Custa aos alunos aceitarem que as células são como seres vivos, que respiram, digerem, reproduzem para manter seu ciclo vital de maneira similar, como os organismos pluricelulares o fazem. Esses autores relatam que os alunos confundem o tamanho de células com o tamanho do organismo e das moléculas, já que são estruturas menores do que um grão de areia, embora nem sempre essa relação seja verdadeira, já que existem as macrocélulas (alvéolo de laranja, fibra de algodão...), que muitas vezes não são referenciadas no ensino. Eles distinguem o núcleo do citoplasma, mas confundem, ainda, membrana plasmática com a parede celular, além de descreverem pobremente as organelas. Essa questão é mais problemática quando eles não concebem que a célula é independente em se tratando de organismo unicelular (bactéria, fungo, protozoário...), sendo dependente diretamente de outras, dentro de um tecido, órgão ou de um sistema vivo, considerando os fatores que interferem no seu funcionamento (nutrientes, temperatura...).

Zamora, Silva e Guerra (1993) discutem questões básicas da biologia celular que estão associadas aos fenômenos cotidianos, tais como estrutura da célula/organismo, herança, reprodução, crescimento, metabolismo, diferenciação celular e organização dos sistemas orgânicos (célula à sistema). Nesse sentido, eles afirmam que a maioria dos alunos do Ensino Médio concebe a célula como estrutura muito obscura. É mais fácil para eles conceberem que o corpo produz 
suas próprias células, tendo o cérebro e o coração controle por sua organização no corpo (visão dominante).

Os alunos do Ensino Médio apresentaram respostas espontâneas para essas questões, muitas vezes, amparadas no finalismo ${ }^{2}$, bem como usam a função para responder aos questionamentos os quais exigem respostas referenciadas num nível científico. Como não têm referentes concretos (objeto sensível ou visível) como apoio às suas respostas, eles se servem da imaginação para explicar os fenômenos/eventos os quais são solicitados, com base no livro didático. Zamora, Silva e Guerra (1993) sustentam que, como forma de suprir tal dificuldade, os alunos repetem a explicação emitida em sala de aula pelo professor para esclarecer as questões emergidas no contexto do ensino. Dessa forma, a concepção animista ${ }^{3}$ desses alunos precisa ser substituída por uma visão sistêmica atual acerca do organismo/célula (lago como ecossistema) numa relação com outros sistemas funcionais que exigem participação do papel vital de organismos de tamanhos e estruturas diferentes, envolvendo variáveis diversas (espécie, anatomia, nutrição, alimento...), por conseguinte, possibilitando desenvolver novos e melhores conhecimentos nos alunos.

Yorek, Sahin e Aydin (2009) afirmam que os estudantes de Ensino Médio usam parâmetros animistas e antropocêntricos como concepção de ser vivo/vida. Eles usam tal princípio para auxiliar na identificação/classificação de animais e plantas e, também, de organismos menores. Como há falta de experiência com seres vivos pequenos na vida cotidiana (microscópicos) e os aspectos de beleza, importância, habitat e movimento não são bem firmados na cognição humana para esses seres vivos, acreditamos que aí reside a dificuldade de caracterização e de reconhecimento deles. Inferimos que isso pode repercutir num menor conhecimento dos alunos do Ensino Médio e da universidade em relação ao organismo/célula.

Tendo em vista que esse é um problema que pode atingir também os alunos da Engenharia de Pesca é que foi direcionada nossa pesquisa antes da realização das aulas pelos professores nos primeiros três semestres do curso. Com isso, esperamos contribuir, criando condições para avaliar os possíveis avanços nos conhecimentos prévios dos discentes do referido curso.

Dentre uma série de aspectos relacionados ao crescimento de seres vivos (especialmente animais e plantas) e na sua relação com o referente concreto, os alunos do Curso Superior de Ciências Biológicas, por exemplo, apresentam pouco desenvolvimento em comparação com os estudantes de Ensino Médio (SHAEFER, 1979). Nesse sentido, os estudos de Shaefer (1979) mostram que os alunos usam como referente concreto medida geométrica, movimento, tamanho e fatores econômicos, sociais e psicológicos quase em igualdade com a diferenciação celular, desenvolvimento, divisão celular e reprodução, hormônios e herança genética. Isso significa que a função biológica de crescimento está atrelada a um sistema interno estendido e depende externamente das condições do meio. De acordo com Vygotsky (1991, 2010), por outro lado e em grande medida, percebemos que os aspectos físicos (tamanho, forma...) apresentados por esses alunos representam uma visão espontânea para a referida função a qual não foi desenvolvida no nível científico nos níveis de escolaridade referenciados. 
Acreditamos, enfim, que a dificuldade de aprendizagem para os estudantes do Ensino Médio e ingressos na universidade decorre de um ensino desenvolvido na escola pela definição de conceitos, ao invés de propiciar condições para eles irem elaborando seus conceitos gradualmente. Para tal, faz-se necessária a diferenciação entre o conceito e uma definição. O conceito científico é construído mediante operações lógicas em que o sujeito vai decompondo traços dos eventos/objetos na sua totalidade, considerando atributos selecionados para tal conceito (forma e tamanho celular, por exemplo). É um processo gradual e dialético baseado em descobrimento, na busca de novas informações, na construção individual ou coletiva de respostas para problemas trazidos da vida cotidiana e/ou escolar. A definição envolve a memorização das propriedades dos objetos/eventos; é uma parte do conceito abordado em sua superfície, tanto para as propriedades gerais, como para as específicas dos objetos/eventos. É um produto final apresentado geralmente no ensino escolar. Por isso que é comum o uso de frases vazias pelos estudantes de diferentes faixas etárias (incluindo os universitários) para definir o conceito antes de este ser dominado e expresso através da linguagem (CASTRO, 2014; GÓMEZ, 2011; SFORNI, 2004). Contudo, destacamos que a transmissão de conhecimentos historicamente produzidos mediante definição conceitual é necessária, uma vez que faz parte das finalidades do Ensino Fundamental e Médio voltadas para minimização das condições de marginalidade dos sujeitos, bem como para a criação de oportunidades de trabalho, embora seja feita de forma deficiente (SAVIANI, 2005).

\section{METODOLOGIA}

\section{Os sujeitos da pesquisa}

Envolve uma turma com 43 estudantes ingressos em 2013.1 no curso de Engenharia de Pesca da Universidade do Estado da Bahia-UNEB, no município de Xique-Xique-BA. Esses alunos têm faixa etária de 17 a 30 anos e não tiveram experiência com o microscópio nos Ensinos Fundamental e Médio.

Entre os alunos entrevistados, existem perfis socioeconômicos diferentes, pois a maioria deles tem formação fundamental e média em rede de ensino pública, com exceções de alguns que estudaram ao menos o curso fundamental em escola particular. Grande parte dos estudantes é natural do município de Xique-Xique, onde moram com os pais, com outros familiares ou já possuem suas próprias famílias. Alguns estudantes, naturais de povoados de Xique-Xique, fixam-se na residência universitária durante o período de estudo no curso. Alguns estudantes, para se manterem economicamente e auxiliarem na renda familiar, trabalham alternando suas jornadas diárias de estudo com as de trabalho, ou prestam serviços na própria universidade como estagiários.

No geral, a experiência cultural da turma é marcada pelas vivências do dia a dia em consonância com os conhecimentos adquiridos na escola. 


\section{Pressupostos}

O trabalho de levantamento de dados na UNEB, Campus XXIV, foi desenvolvido com base no método descritivo/explicativo ${ }^{4}$, que possibilita a compreensão das formas de pensamento dos estudantes, tanto nas suas características mais gerais, como nas específicas. Para tal, mencionamos três fases da construção do conhecimento escolar que coadunam com conceitos fundamentais da Teoria Histórico-Cultural de Vygotsky, ora referenciados neste trabalho: prática-teoria-prática partindo do nível de desenvolvimento atual dos alunos, trabalhando na zona de desenvolvimento imediato, para chegar a um novo desenvolvimento atual. Essas fases são definidas a partir dos passos a seguir:

\footnotetext{
1) O primeiro passo é a Prática Social Inicial do conteúdo ou do conceito que se expressa pela vivência cotidiana na totalidade empírica; 2) O segundo passo é a Teorização que consiste na explicitação da dimensão científica do conteúdo ou do conceito, ou seja, é o estudo do conhecimento historicamente produzido e sistematizado; 3) O terceiro passo é o retorno à prática, agora como Prática Social Final do conteúdo, que deverá ser usado para a transformação da realidade. (GASPARIN, 2007, p. 9)
}

Iniciamos o trabalho investigativo no nível de desenvolvimento atual ou Zona de Desenvolvimento Real (ZDR) dos alunos (conhecimentos espontâneos e escolares), com vistas a levantar os conhecimentos prévios dos alunos do primeiro semestre do curso de Engenharia de Pesca da UNEB, Campus XXIV, sobre ser vivo/célula. Por meio desse diagnóstico, descrevemos a prática inicial dos conteúdos proposta por Gasparin (2007). Este poderá ser usado como base para compreensão dos avanços dos conhecimentos dos alunos em relação à prática a ser desenvolvida pelos professores no semestre atual e nos seguintes $\left(2^{\circ}\right.$ ao $4^{\circ}$ semestre).

\section{A pesquisa qualitativa}

Usamos a pesquisa qualitativa vinculada à entrevista estruturada (questionário) para o levantamento de dados acerca da identificação dos conhecimentos prévios dos alunos sobre os conceitos de seres vivos (estrutura celular, grupos, tamanho, ciclo de vida e funções vitais). A abordagem qualitativa poderá permitir ao pesquisador ir além da superfície dos eventos, determinar significados, muitas vezes ocultos, interpretá-los, explicá-los e analisar o impacto na vida em sala de aula (BOGDAN; BIKLEN, 1994).

A coleta de dados envolveu 43 alunos ingressos no Curso de Engenharia de Pesca da UNEB-Campus XXIV. Essa turma foi escolhida por conta da falta de pré-requisitos em biologia celular para as disciplinas introdutórias do curso indicadas pelos professores e pelos próprios estudantes. Eles aceitaram participar da pesquisa com a condição de que esta pudesse contribuir de alguma forma para melhoria na aprendizagem deles. Para tal, propusemos a realização de um planejamento com os professores do ciclo básico, bem como de um curso de 
extensão de biologia celular prática. Inicialmente, efetuamos uma entrevista estruturada (ee1) com toda a turma. Essa etapa teve duração de 1 hora/aula.

A aplicação do questionário ocorreu na sala de aula do Departamento de Ciências Humanas e Tecnologias - DCHT/Campus XXIV, conforme cronograma previamente combinado com a coordenação, os professores e os sujeitos da pesquisa. Foi aplicado no início do semestre 2013.1 para todos os alunos, numa aula cedida por um dos colegas, no primeiro dia de aula.

Os conteúdos usados para a composição do questionário foram, de uma forma geral, estrutura/tamanho e função de seres vivos. Eles foram desdobrados nos seguintes aspectos: ser vivo, número de células, célula, diferenciação celular, composição química da célula, transporte e absorção de nutrientes e crescimento. De uma forma geral, as questões foram divididas em dois aspectos principais: estruturais e funcionais. As primeiras (questões de $n^{\circ} 1$ a 4 , Quadro 1) requisitam respostas diretas ou imediatas para os assuntos ora mencionados; as segundas (questões de $\mathrm{n}^{\circ} 5$ a 10, Quadro 1), respostas explicativas ou mediatas (CASTRO, 2014; TRIVIÑOS, 1987). Foram dados nomes fictícios aos estudantes para fins de preservar suas identidades e facilitar a análise de dados.

Segundo Milles e Huberman (1994), a análise de dados tem como objetivo dar sentido aos dados coletados, apresentando resultados e levando conclusões para o estudo. Da mesma forma, intencionamos observar quais conceitos os alunos apresentam antes das aulas ministradas pelos professores nos três semestres letivos subsequentes a essa fase de pesquisa.

Os dados coletados foram analisados de modo que as respostas dos alunos fossem agrupadas em categorias conceituais e comparadas (Quadro 1). Para isso, consideramos que os conhecimentos levantados refletem a relação dos conteúdos/ conceitos que se expressam pela vivência cotidiana na totalidade empírica. As respostas dos alunos foram categorizadas da seguinte forma:

1) Sem Rendimento ( $S / R)$ - consideramos sem rendimento a ausência de resposta, ou aquela fundamentada erroneamente;

2) Ultra Espontânea (U/E) - resposta espontânea baseada na imaginação do aluno e/ou influenciada por essa forma de pensamento compartilhada pelas pessoas em seu meio social (referenciada na vivência concreta do seu meio social);

3) Espontâneo (E) - resposta espontânea referenciada na vivência concreta em seu meio social;

4) Espontâneo de Transição (E/T) - resposta influenciada pelo ensino escolar e por profissionais do seu meio social que dominam os conceitos científicos, mas que não se descolam completamente da sua vivência empírica;

5) Científico (C) - resposta adquirida mediante o ensino escolar ou influenciada pelos profissionais do seu meio social que dominam os conceitos científicos.

Essas categorias foram construídas a partir das etapas do desenvolvimento humano que precedem a formação de conceitos (VYGOTSKY, 2010). Esse autor assegura que a imaginação é a forma mais elementar de conhecimento espontâneo e que esta pode ascender ao conhecimento científico, com a contribuição do ensino escolar ou de pessoas que dominam tal forma de conhecimento. Vale ressaltar que, para Vygotsky, o conhecimento científico equivale ao conhecimento escolar ensinado pelo professor em sala de aula (CASTRO, 2014). 


\section{OS CONHECIMENTOS PRÉVIOS DOS ALUNOS DO CURSO DE ENGENHARIA DE PESCA SOBRE ESTRUTURA E FUNÇÃO CELULAR (SER VIVO/CÉLULA)}

A partir do levantamento de dados empíricos (questionário), elaboramos um diagnóstico acerca dos conhecimentos prévios dos alunos ingressos no curso de Engenharia de Pesca, no primeiro semestre do ano de 2013 (Quadro 1).

As respostas dos (as) alunos (as) ao questionário foram agrupadas em três aspectos principais, a saber: Sem Rendimento (S/R), Espontâneo (E) e Científico (C).

\section{Sem Rendimento (S/R)}

Os(as) alunos(as) apresentaram menor rendimento (ausência de conhecimentos prévios) para as questões 2, 3, 4 e 5, com 21, 21, 28 e 38 respostas sem rendimento, respectivamente (Quadro 1). Com base em Zamora, Silva e Guerra (1993) e Castro (2010, 2014), por se tratar de assuntos específicos relacionados ao tamanho do ser vivo/célula, à composição química e ao metabolismo (função vital), acreditamos que a falta de conhecimento dos alunos para tais conceitos pode estar atrelada à deficiência na formação de professores na área de Ciências/ Biologia. Contudo, ressaltamos que as dificuldades de acesso ao conhecimento desses alunos no seu dia a dia referentes a materiais instrutivos educativos disponibilizados em casa/escola, as vivências sociais compartilhadas em nível de troca de informações, o contato tardio com os conceitos científicos, o grau de instrução familiar e as suas necessidades de vida voltadas para sobrevivência, entre outros, sobremaneira podem influenciar a aquisição de novos conhecimentos na área de biologia celular.

Para a questão 5 "como é mantida a composição química de um ser vivo/célula e qual a importância disto para os seres vivos?” e para a 10 "como crescem: animal, planta e você?", houve, respectivamente, 1 e 5 respostas ultra espontâneas, conforme evidenciamos nos exemplos a seguir:

\footnotetext{
Fernanda - Sendo abastecida pelos alimentos, para o organismo sobreviver bem e com saúde; Rosa - Plantas: germinação; Animal: gestação; Eu: gestação; Alfredo - Através de uma boa alimentação e cuidados essenciais ao seu desenvolvimento; Joaquim - As células se desenvolvem com o passar do tempo e vão passando por estágios específicos de acordo com a função de cada uma. Com o tempo, ao chegar ao estágio final, elas crescem; Fernanda - Todos os três precisam ser alimentados. Animal: são alimentados pelos pais, que os ajudam, depois viram competidores para sobreviver. Planta: precisa de adubo, mutação, para dar bons frutos. Ser humano: não muito diferente, vai seguindo os exemplos dos pais e destacando na sociedade; Alfredo - Acho que ambos precisam de cuidados, mas como a convivência em diferentes habitats, cada um aprende de maneiras diferentes (estudantes de Engenharia de Pesca, 2013).
}

A primeira questão envolve o conceito de nutrição, e a segunda, o conceito de crescimento. Ambos são conceitos centrais para os quais os estudantes tiveram dificuldades de formular respostas espontâneas, tendo como base algo concreto ou empírico. Eles emitiram suas respostas com 
base na imaginação ou na intuição. Esse tipo de pensamento pode ser entendido como uma forma de transição entre as respostas sem rendimento e o conhecimento espontâneo propriamente dito. Para esses tipos de quesito, a intuição parece ser mais genuína, porque muito se distancia da vivência concreta real dos conteúdos (CASTRO, 2014).

Para a questão 1, a estudante Ana acredita que a célula/ser vivo é autossuficiente para manter a sua composição química, e que isso garante a sua importância para o organismo. Há, portanto, um fim em si mesmo, que fundamenta a estrutura e a função do mundo vivo (pensamento finalista). Na segunda questão, emergem associadamente as formas de pensamento finalismo, animismo e antropocentrismo para os estudantes Rosa, Antônio, Joaquim, Fernanda e Alfredo em relação aos seguintes aspectos: gestação/germinação, desenvolvimento celular, alimentação, cuidados essenciais, cuidado parental, destaque social, convivência, aprendizagem diferente são fatores indispensáveis para o crescimento de um ser vivo. Com base em autores como Castro (2010, 2014), Yorek, Sahin e Aydin (2009) e Zamora, Silva e Guerra (1993), as respostas ultra espontâneas são decorrentes da falta de referente concreto, de experiência com esses assuntos, bem como da compreensão do significado desses termos, ainda que sejam espontâneos. Para Vygotsky (1991, 2000, 2010), um conceito científico só inicia seu desenvolvimento quando o seu correspondente estiver dominado no nível espontâneo, ou seja, quando o estudante for capaz de explicar sobre os objetos/eventos de forma lógica, consciente e sistematizada (explicar o cuidado dos pais com fisiologia, genética, evolução e a alimentação com a nutrição...)

\section{Espontâneo}

A categoria conhecimento espontâneo (E) foi tomada como base para elaboração de novos conhecimentos. Para Castro (2010, 2014), quando o aluno tem conhecimento espontâneo para determinado conteúdo escolar, isso facilita o desenvolvimento do conhecimento científico correspondente, pois tal condição motiva a busca de compreensão sobre os objetos/fenômenos que são levados para sala de aula por ele ou pelo(a) professor(a). Por outro lado, a ausência de conhecimento cotidiano em relação aos conteúdos escolares torna mais difícil a interação dos estudantes com a matéria ensinada, bem como impossibilita uma aprendizagem sobre tais assuntos de maneira efetiva e com significado para a sua formação profissional.

Os alunos apresentaram um alto número de respostas espontâneas para as questões $1,3,6,7,8,10$, tendo respondido respectivamente 25, 21, 33, 16, 17 e 19 alunos. O menor número de respostas espontâneas foi apresentado para as perguntas 2, 4 e 5, para as quais responderam respectivamente 8, 3 e 4 alunos (ver Quadro 1). A diferença nos resultados para essas questões é decorrente da razão de os estudantes terem uma vivência em seu meio com esses assuntos (YOREK; SAHIN; AYDIN, 2009; ZAMORA; SILVA; GUERRA, 1993) influenciada pela referência que têm acerca de seres vivos macroscópicos, como plantas, animais e o próprio ser humano, ou seja, na estrutura e no funcionamento desses organismos. Eles asseguram suas formas de pensar com maior ou menor explicação a depender 
da relação que tais conteúdos têm com os conceitos ensinados na escola e com o nível de assimilação efetivado para os referidos assuntos. Como esses assuntos geralmente não são ensinados na escola básica, com vistas a ampliar a compreensão dos estudantes sobre a estrutura e a funcionalidade de seres vivos, então eles usam a imaginação para responder às questões com menos explicação.

O menor número de respostas espontâneas para as questões 2, 4 e 5 tem um significado especial, para o qual se direciona este estudo, pois, se os estudantes não têm uma referência conceitual para os conteúdos supramencionados, verificase a necessidade de incorporá-los no currículo do ensino universitário. Assim, poderão ser criadas condições para que novos conceitos possam ser mobilizados, juntamente com os alunos, como ponto de partida para elaboração de formas de pensamento mais abstratas voltadas para explicação de fenômenos/eventos em sua realidade concreta. O número de respostas espontâneas para as questões funcionais foi maior do que para as estruturais (cf. Quadro 1). Como exemplos de respostas espontâneas estruturais para as questões de $n^{\circ} 1$ a 4 (1 - O que é um ser vivo? Descreva; 2 - Quais os seres vivos/células que você conhece (amicroscópicos, b- pluricelulares pequenos e c- células macroscópicas)?; 3 - Que tamanho você acha que tem uma célula em relação aos seres vivos pequenos que você observa ao olho nu?; 4 - Qual a composição de uma célula?), temos, respectivamente (uma resposta para cada questão): Juca - É um ser que depende de partículas que são encontradas no seu ambiente que vive; Júlia - a- "Bactérias", b- "Contém duas ou mais células; c- "São as que podem ver a olho nu”; Daniel - "muito pequena"; Luana - "Por nutrientes, para se desenvolver principalmente". Como exemplos de respostas espontâneas funcionais para as questões de $\mathrm{n}^{\circ} 5$ a 10 (5 - Como é mantida a composição química de um ser vivo/célula e qual a importância disto para os seres vivos? 6 - Todas as células de um organismo são iguais? Sim 0 Não O Por quê?; 7 - O que é uma célula e como ela funciona?; 8 - Como os nutrientes chegam às células de um (a) micro-organismo, animal e planta?; 9 - O que acontece com esses nutrientes dentro de uma célula?; 10 - Como crescem: animal, planta e você?), temos, respectivamente (uma resposta para cada questão):

\footnotetext{
Matheus - Através do ambiente em que se encontra. Porque uns dependem dos outros para garantir a sobrevivência; Bianca - Não. Porque tem células com estrutura diferentes; Miguel - É um tipo de parede do organismo, ela funciona como um tipo de energia para fortalecer o ser vive; Juca - através de partículas muito pequenas; B) de plantas e outros animais; Bianca - Acredito que é feita uma separação e uma distribuição adequada dos nutrientes; Milena - Ambos se alimentando (estudantes de Engenharia de Pesca, 2013).
}

Acreditamos que as formas de pensamentos expressas pelos estudantes acima mencionados derivam da falta de experiências deles com os seres microscópicos, bem como do pouco entendimento que eles têm acerca do conceito de vida (científico e central), o qual é pouco explorado na escola básica (YOREK; SAHIN; AYDIN, 2009; YOREK; SAHIN; UGULU, 2010).

Para a terceira questão, que versa sobre a relação entre o tamanho de uma microcélula e um organismo pluricelular pequeno, observamos, apenas como fundamento para as respostas dos alunos, a intuição, dada a não experiência 
com uso do microscópio e/ou com aulas viabilizadas com estudo de imagens provenientes do livro didático ou de outros recursos facilitadores da visualização dos conteúdos biológicos (aulas ilustradas no quadro, slides...), como ilustram os exemplos: Miguel - "Na minha ideologia é a comparação de uma bola de futebol a um grão de areia"; Bruno - "Naturalmente um tamanho equivalente a cinquenta vezes menor que os seres vivos observados a olho nu"; Alfredo - "Eu acho que milhares de vezes menores. Não sei exatamente o tamanho".

Por essa razão, é fundamental que a universidade se atente à busca de alternativa para oferecer conteúdos mínimos aos alunos ingressantes, os quais não tiveram oportunidade de aprender na formação básica, como meio de minimizar as dificuldades de aprendizagem encontradas por estes no curso de graduação, no caso específico na área de Engenharia de Pesca. Para esse tipo de quesito, a intuição se aproxima da vivência concreta dos conteúdos, influenciada por referências em relação ao tamanho dos objetos, ainda que seja de forma muito superficial ou geral (pequeno, grande, pesado, leve...).

Identificamos nas respostas dos estudantes de Engenharia de Pesca os pensamentos espontâneo e conceitual associados (espontâneo de transição). Isso foi observado nas questões 1,7 e 8 , respectivamente ( $\mathrm{O}$ que é um ser vivo? Descreva; O que é uma célula e como ela funciona?; Como os nutrientes chegam às células de um (a) micro-organismo, animal e planta? ), como expressam alguns exemplos: Laura - "É todo ser que contém célula, que se pode reproduzir apesar de existir seres sem célula, mas ocorre a reprodução"; Vinícius - "Célula é formada por organismos vivos. Elas possuem a informação genética e também outros itens de sobrevivência"; Vera - "Pelo organismo do intestino dos animais, pela corrente sanguinea, epela raiz das plantas". Para a primeira questão, a aluna Laura inicia a elaboração de uma reposta científica, mas finaliza o pensamento de forma equivocada, afirmando que existem seres vivos sem célula e que se reproduzem. Esse tipo de resposta deve ser influenciado pelos conteúdos apresentados, principalmente, pelos livros didáticos de Ensino Fundamental e Médio, que apresentam o vírus como ser não vivo, mas que se reproduz. Para o sétimo item, o aluno Vinicius emite uma inversão de pensamento (troca da causa pelo efeito, comum no pensamento espontâneo) ao afirmar que a célula é formada por organismos vivos, embora sinalize uma compreensão inicial sobre a estrutura e o funcionamento celular. Para o oitavo quesito, há uma apropriação básica acerca da aquisição de nutrientes por micro-organismos, animais e plantas influenciada pelo ensino escolar. Entretanto, tal compreensão é apresentada na sua forma superficial e/ou inicial, sem evidenciar qualquer relação com os tipos de transportes envolvidos (passivo/ativo), acompanhada de um equívoco conceitual, no que diz respeito à assimilação de nutrientes já prontos pela raiz, salvo os minerais. Para essas questões, fica minimizada uma explicação mais generalizada (ampla), lógica e sistematizada. Isso evidencia que esses estudantes estão em processo de desenvolvimento do conhecimento científico com relação a essas questões (CASTRO, 2014). 


\section{Científico (C)}

A categoria conhecimento científico (C) foi usada como ponto para o qual o conhecimento deve ser alcançado.

No nível científico, as respostas apresentadas pelos alunos para as questões estruturais e funcionais foram, em número, praticamente iguais, por conta da dificuldade de compreensão deles com relação aos assuntos de seres vivos/célula (ver Quadro 1). Como exemplo dessas formas de pensamento, apresentamos, respectivamente, duas repostas para a questão 4 - "Qual a composição de uma célula”? e para a questão 7 - "O que é uma célula e como ela funciona?”: Matheus - "Membrana plasmática, citoplasma, ribossomos, mitocôndria etc." e Vinícius - "Núcleo, proteinas, componentes genéticos, orgânulos; Joana - "A célula é a unidade morfofisiológica dos seres vivos" e Pedro - "É a menor divisão de um todo e funciona através de seu núcleo". Isso evidencia que tais conceitos têm uma relação original em seu desenvolvimento, no processo de formação do intelecto humano, ou seja, o conceito espontâneo é base para a formação do científico, e este contribui para o enriquecimento das ideias espontâneas, conforme assinala Vygotsky (1991, 2010).

Para as questões 2 e 3 , que tratam da diferenciação entre organismos micro e macroscópicos, incluindo organismos pluricelulares pequenos e macrocélulas, quase metade da turma não apresentou respostas (S/R). Isso pode ser explicado pela dificuldade que os alunos têm em conceber a célula como organismo independente, quando ela é o próprio organismo; ou, ainda, como interdependente, quando ela faz parte do corpo de organismo que tem muitas células (ZAMORA; SILVA; GUERRA, 1993). Esse problema também se relaciona com a limitação dos alunos para diferenciar esses seres vivos quanto aos aspectos microscópicos, ou, ainda, para diferenciação pela forma/estrutura, o que depende de uma compreensão do conceito de diferenciação celular (conceito científico e derivado). Contudo, para esse último aspecto conceitual, apenas 10 estudantes não usaram tal ponto de vista para fundamentar suas respostas em relação à questão 6 "Todas as células de um organismo são iguais? Sim () Não () Por quê”?, ou seja, não apresentaram rendimento (S/R), enquanto 33 deles apresentaram respostas espontâneas.

Os dados acima apresentados evidenciam que o conceito de diferenciação celular pode ser menos limitante para a formação do conceito científico do que o conceito de tamanho, pois os conhecimentos prévios apresentados por esses alunos para a referida questão servem de base para edificação do pensamento conceitual, se para tal finalidade o ensino for direcionado. Quando o estudante não tem conhecimento prévio sobre determinado conceito ou conteúdo, como no caso de tamanho de ser vivo/célula, é necessário que o (a) professor (a), ainda que na universidade, favoreça a formação desse conhecimento. Para isso, é preciso que o (a) professor (a) apresente exemplos concretos sobre o assunto, não apresentados no Ensino Médio (observar macrocélulas como fibra de algodão, alvéolo do limão etc. e lâminas microscópicas prontas...). Como se trata de um conceito derivado, ao mesmo tempo, esse ponto de partida pode favorecer o desenvolvimento do pensamento conceitual (em rede) dos alunos incluindo outros conceitos, como diferenciação celular, crescimento, entre outros (CASTRO, 2014). 
Foram observadas respostas mais bem-elaboradas para os quesitos 2, 4, 8 e 10 por 14, 12, 9 e 10 alunos, respectivamente. Entretanto, para as questões 1, 3, 7 e 9, não houve tal desenvolvimento, sendo que foram respondidas apenas por 3,1, 2 e 1 alunos, respectivamente. Analisamos duas situações extremas, no que tange ao domínio dos conteúdos pelos estudantes: a primeira, em que eles apresentaram conhecimento significativo em relação ao total de questões respondidas; a segunda, em que a turma não sinalizou conhecimento no nível científico, considerando os aspectos estruturais e conceituais das respostas. As respostas com êxito para questões funcionais (espontâneas e científicas), mesmo considerando as limitações dos alunos, decorrem do uso indireto que fazem do conhecimento adquirido em sala de aula, ensinado pelos professores ou assimilados superficialmente a partir do livro didático, como asseguram Zamora, Silva e Guerra (1993). Para os conteúdos (questão 2) relacionados a "Quais os seres vivos/células que você conbece (microscópicos, pluricelulares pequenos e células macroscópicas)?”, a melhor assimilação dos alunos pode ser associada às influências do ensino escolar capazes de provocar avanços conceituais, mesmo considerando os óbices ora relatados (falta de aulas práticas, incluindo o uso de microscópio). Já para os assuntos ( $8^{\mathrm{a}}$ questão) "Como os nutrientes chegam às células de um(a) micro-organismo, animal e planta", podemos inferir que as aulas ministradas na educação básica não foram suficientes para ampliação dos conceitos nessa área. Nesse sentido, a nossa proposição de ensino mediante formação de conceitos é apresentada como mais uma alternativa ao ensino com vistas a contribuir com a minimização e/ou a superação das dificuldades de aprendizagem dos estudantes de graduação em biologia celular. Tal propósito não considera que os estudantes têm uma limitação ou déficit conceitual, mas que possuem uma "bagagem" de conhecimento com sua história, que deriva do ensino que receberam anteriormente ao ingresso na universidade e das experiências adquiridas a partir das condições socioculturais e econômicas de seu meio.

Esse ponto de vista tem apoio nos trabalhos de Zamora, Silva e Guerra (1993) e de Bahar, Johnstone e Hansell (1999), que reconhecem as falhas do ensino escolar, mas acreditam na eficácia deste quando voltado para as necessidades de aprendizagem dos alunos. Percebemos que a visão que possuem acerca do conteúdo escolar e de meio para o conceito de crescimento de ser vivo influencia mutuamente na diferenciação dos organismos micro e macroscópicos, incluindo as macrocélulas. Essa é uma opinião que está de acordo com a tese de Vygotsky, anteriormente relatada, a qual contribui para ampliação da derivação conceitual por meio dos conceitos centrais. Mas, se menos da metade dos alunos não sinaliza conhecimento construído em relação aos itens supramencionados, isso evidencia que a derivação conceitual mediante os conceitos centrais (CABALLER; GIMÉNEZ, 1993; CASTRO, 2014; MOURA, 2000; SHAEFER, 1979) pode ser minimizada se a escola e a universidade oferecem condições materiais (professores e recursos didáticos apropriados) para suscitar avanços na aquisição de conceitos científicos pelos alunos; outrossim, as dificuldades de compreensão conceitual dos alunos nessa área, que poderiam ser possibilitadas por tal processo, colocam-se como algo intransponível para os dias atuais, em que se observa inegavelmente a falta de pré-requisitos para os referidos conteúdos nos alunos ingressos na 
universidade, como é o caso dos estudantes do curso de Engenharia de Pesca, UNEB, Campus XXIV (Quadro 1).

Quadro 1 - 0 conhecimento dos alunos sobre estrutura e função celular

\begin{tabular}{|c|c|c|c|c|c|}
\hline ESTRUTURA/CATEGORIAS & SS/R & UUE & EE & $\mathrm{EE} / \mathrm{T}$ & CC \\
\hline 1- 0 que é um ser vivo? Descreva. & - & - & 25 & 15 & 3 \\
\hline $\begin{array}{l}\text { 2- Quais os seres vivos/células que você } \\
\text { conhece (a-microscópicos, b- pluricelulares } \\
\text { pequenos e c-células macroscópicas)? }\end{array}$ & 21 & - & 8 & - & 14 \\
\hline $\begin{array}{l}\text { 3- Que tamanho você acha que tem uma } \\
\text { célula em relação aos seres vivos pequenos } \\
\text { que você observa ao olho nu? }\end{array}$ & 21 & - & 21 & - & 1 \\
\hline 4- Qual a composição de uma célula? & 28 & - & 3 & - & 12 \\
\hline \multicolumn{6}{|l|}{ FUNÇÃO/CATEGORIAS } \\
\hline $\begin{array}{l}\text { 5- Como é mantida a composição química } \\
\text { de um ser vivo/célula e qual a importância } \\
\text { disto para os seres vivos? }\end{array}$ & 38 & 1 & 4 & - & - \\
\hline $\begin{array}{l}\text { 6- Todas as células de um organismo são } \\
\text { iguais? } \\
\text { Sim () Não () Por quê? }\end{array}$ & 10 & - & 33 & - & - \\
\hline 7- 0 que é uma célula e como ela funciona? & 16 & - & 16 & 9 & 2 \\
\hline $\begin{array}{l}\text { 8- Como os nutrientes chegam às células } \\
\text { de um(a) micro-organismo, animal e planta? }\end{array}$ & 13 & - & 17 & 4 & 9 \\
\hline $\begin{array}{l}\text { 9- } 0 \text { que acontece com esses nutrientes } \\
\text { dentro de uma célula? }\end{array}$ & 18 & - & 24 & - & 1 \\
\hline 10- Como crescem: animal, planta e você? & 9 & 5 & 19 & - & 10 \\
\hline
\end{tabular}

Fonte: Entrevista com alunos (43) do $1^{\circ}$ semestre do curso de Engenharia de Pesca - UNEB/Campus-XXIV, 2013. Legenda: $S / R=$ Sem Rendimento; $U / E=$ Ultra Espontânea; $E=$ Espontâneo; $E / T=$ Espontâneo de Transição; $C=$ Científico

Para a primeira questão "O que é um ser vivo? Descreva", observamos uma maior variedade de aspectos conceituais: célula, ciclo vital, função vital, vida e ambiente. As respostas dos(as) alunos(as) para essa questão foram também agrupadas em três aspectos principais, a saber: Espontâneo (E), Espontâneo/ Transição e Científico (C), como expresso no Quadro 2, a seguir: 
Quadro 2 - A derivação conceitual e a formação de conceitos

\begin{tabular}{|c|c|c|c|}
\hline Conhecimento/ categorias & Espontâneo (e) & $\begin{array}{c}\text { Espontâneo/ } \\
\text { transição (e/t) }\end{array}$ & Científico (c) \\
\hline Célula & - & 11 & 1 \\
\hline Ciclo vital & 5 & 1 & 1 \\
\hline Função vital & 5 & 3 & - \\
\hline Vida & 8 & - & 1 \\
\hline Ambiente & 7 & - & - \\
\hline
\end{tabular}

Fonte: Entrevista com alunos (43) do $1^{\circ}$ semestre do curso de Engenharia de Pesca-UNEB - Campus-XXIV, 2013.

A primeira questão envolve os conceitos de célula, ciclo vital, vida, função vital e ambiente. Os conceitos de vida e ambiente são centrais ou primitivos, assim como o de ser vivo, e estão inter-relacionados, como os derivados (célula, ciclo vital, função vital). O maior número de respostas para os níveis de conhecimento espontâneo e transição evidencia que os conceitos centrais e derivados estão imbricados numa mesma base de compreensão para os estudantes de Engenharia de Pesca. A ausência da forma de conhecimento espontâneo de transição para o conceito de vida e de ambiente indica que há uma maior dificuldade de estes serem dominados no nível científico, implicando falhas na derivação conceitual, uma vez que apenas um aluno apresentou domínio conceitual para o conceito de vida e nenhum domínio para o conceito de ambiente. A limitação para o pensamento conceitual para essa questão remete à dificuldade de os alunos conceberem a célula como a unidade básica da vida, ou seja, como a parte morfológica e funcional do organismo uni ou pluricelular, bem como da falta de um ensino partindo dos conceitos primitivos, a fim de promover uma maior derivação conceitual (YOREK; SAHIN; UGULU, 2010).

Por outro lado, o pensamento espontâneo evidenciado na maioria das respostas dos alunos pode ser explicado pelo uso de tais parâmetros, assim como pela falta de experiência com o microscópio, e de exemplos práticos da vida cotidiana de como são estruturados e funcionam os seres vivos pequenos (YOREK; SAHIN; AYDIN, 2009). A falta de pensamento espontâneo sobre célula deve ser entendida pela razão de esses alunos nunca terem tido aulas práticas com o microscópio ou de a escola básica não ter apresentado para eles exemplos concretos de macrocélulas (algodão, ovo, alvéolos de limão...). Os conceitos em transição parecem refletir a visão de célula preconizada pelos livros didáticos e aulas ministradas pelos professores dos Ensinos Fundamental e Médio.

Para fins de ilustrar as formas de pensamento/categorias aqui discutidas (Quadro 2), apresentamos alguns exemplos (um para cada forma de pensamento/ categoria, respectivamente), a seguir:

1) Célula-Espontâneo de Transição (E/T)/Científico (C) - João - "Ser vivo é tudo aquilo que tem vida e contém célula"; Gabriela - "Todo ser que respira e é constituido por célula". 
2) Ciclo Vital - Espontâneo (E)/ Espontâneo de Transição (E/T)/ Científico (C) - Lucas - "Ser vivo é tudo o que nasce, cresce e morre"; Ana - "É um ser capaz de realizar funções como, respirar e reproduzir e que nasce, cresce e morrem"; Vinícius - "Ser vivo é tudo o que possui vida, independente de tamanho, ou seja, pulsa vida e também pode ser considerado aquele que nasce, cresce se reproduz e morre".

3) Função Vital - Espontâneo (E)/ Espontâneo de Transição (E/T) - Miguel - "É tudo que necessita de oxigênio"; Joaquim - "É algo que possui oxigênio, vida, respiração, células etc.”.

4) Vida - Espontâneo (E)/ Científico (C) - Helena - "É algo ou uma coisa que está viva e é um ser do mundo, ou seja, que faça parte do planeta. Pode ser eles racionais ou irracionais e outros"; Lúcia - "Ser vivo é um ser que tem vida e produz células."

5) Ambiente - Espontâneo (E) - Luciano - "É tudo o que habita na terra".

Em relação ao primeiro item, o conceito científico (aluna Gabriela) se diferencia do espontâneo de transição por associar a célula quanto à estrutura a uma função (respiração), embora seja uma explicação fraca, mas que já sinaliza um domínio conceitual. O aluno João apenas cita os conceitos de vida e célula como explicação memorizada, mas que evidencia uma percepção da relação entre o conceito primitivo de vida e o derivado, célula, a qual pode ser ampliada pelo ensino desses conceitos dentro de uma rede sistêmica. O conceito de ciclo vital no nível científico (aluno Vinícius), para o segundo item, diferencia-se do nível espontâneo de transição por relacionar os conceitos de vida, tamanho, energia (pulsa a vida) e ciclo vital, ampliando a compreensão da rede conceitual, tanto nos aspectos estruturais (tamanho), como nos funcionais (vida, energia, ciclo vital); as formas de pensamento da aluna Ana se ampliam em relação ao Lucas pelo fato de relacionar a função vital (respirar, reproduzir) ao ciclo vital (nascer, crescer e morrer), indicando pequeno pensamento em rede ou explicação, enquanto Lucas menciona apenas o ciclo vital. Igualmente ocorre para o quesito 3, em que o aluno Joaquim relaciona os conceitos funcionalidade (vida e respiração) com o de célula, enquanto Miguel menciona apenas o conceito de respiração para descrição de ser vivo. O conceito científico de vida é evidenciado na resposta da aluna Lúcia, ao descrever o que é um ser vivo, pois relaciona a esse aspecto a produção de células, que sugere a aquisição inicial da consciência, da generalização conceitual e do pensamento deliberado.

Em geral, o grande número de respostas espontâneas dos alunos sobre ser vivo está associado ao uso do finalismo, animismo/antropocentrismo, que fundamenta suas formas de pensamento durante o desenvolvimento, mas que se estende à idade adulta (YOREK; SAHIN; AYDIN, 2009; ZAMORA; SILVA; GUERRA, 1993). Contudo, ressalvamos que isso é decorrente da pouca atenção que a escola presta ao ensino do conceito de vida, tendo como base a biologia celular, sendo que este, uma vez construído, poderá trazer aumento do conhecimento desses estudantes para outros conceitos biológicos, os quais podem ser derivados da concepção de ser vivo/vida. 


\section{CONSIDERACְÕES FINAIS}

No geral, houve um predomínio das respostas espontâneas sobre as científicas, sendo que, para a maioria das questões, os alunos não apresentaram rendimento. $\mathrm{O}$ conhecimento dos alunos para questões estruturadas foi praticamente equivalente para questões funcionais, sendo este limitado para os conceitos centrais. Este trabalho poderá fornecer aos professores do Curso de Engenharia de Pesca as formas de conhecimentos dos alunos, o que poderá auxiliálos no desenvolvimento e no aprofundamento dos conteúdos das disciplinas da área biológica, com implicações na formação profissional desses estudantes.

Isso pode implicar na execução do papel da universidade quanto a suprir parte de uma lacuna não preenchida na escola básica, pois, conhecendo as dificuldades e as potencialidades dos alunos, poderá esta contribuir para a realização de um planejamento de ensino no Curso de Engenharia de Pesca, bem como favorecer a continuidade da pesquisa na área. Tal planejamento deve contemplar um ensino de conceitos com cuja assimilação os alunos têm dificuldades, devido aos conhecimentos prévios deles.

Isso evidencia que a dificuldade de assimilação dos conteúdos dos alunos pode ser minimizada e/ou superada com a incorporação de componentes curriculares na área de biologia celular no Curso de Engenharia de Pesca da UNEB, Campus XXIV, ou mediante direcionamento das suas ementas/conteúdos das disciplinas biológicas para o ensino de assuntos básicos de Biologia.

No semestre 2015.1, foi desenvolvida a segunda etapa deste trabalho, a fim de analisar quais conceitos os alunos apresentam após as aulas ministradas pelos professores nos três semestres letivos subsequentes ao período 2013.1. Isso possibilitou uma melhor comparação e discussão acerca do tema e do processo de ensino-aprendizagem da construção de conceitos científicos, bem como suscitou a realização de um curso de extensão de biologia celular prática como meio de minimizar as dificuldades, caso apresentadas.

Este trabalho, enfim, ainda que de forma preliminar e apoiado na Teoria Histórico-Cultural de Vygotsky, enfatiza uma abordagem sistêmica para o ensino dos conceitos de ser vivo/célula a partir dos conhecimentos prévios dos estudantes universitários. Para tal, os conceitos espontâneos e científicos são compreendidos em forma de rede conceitual na qual, ora eles aparecem como centrais, ora como derivados, sendo que o desenvolvimento de cada um é influenciado pelo outro. Assim, estará sujeito a novas contribuições de profissionais que se interessarem pela pesquisa na área e/ou se servirem da presente abordagem para o ensino.

\section{NOTAS}

${ }^{1}$ Os sujeitos em formação, especialmente as crianças (0-3 anos de idade), não usam critérios (atributos) para organizar os objetos (amontoados vagos de objetos desiguais); por isso, os fatores 
perceptuais são irrelevantes nessa organização (agregação desorganizada), ou seja, não há distinção na percepção dos objetos.

2 Forma de pensamento (raciocínio teleológico) voltada para atender às necessidades próprias dos seres vivos e para dar aos objetos características visíveis e não visíveis (CASTRO, 2014, p. 26).

${ }^{3} \mathrm{O}$ sujeito percebe o mundo como uma extensão à sua imagem, animado da mesma forma que ele mesmo (um ser bruto é valente). É uma forma de pensamento que faz parte do egocentrismo da criança, mas que pode continuar nos adolescentes e nas pessoas adultas (CASTRO, 2014, p. 26).

${ }^{4}$ O método descritivo baseado nas características externas (fenótipo) representa o início em que o objeto/fenômeno é observado; o método explicativo (genético) favorece a explicação de um fenômeno/objeto, com base na sua origem, possibilitando a revelação das suas bases dinâmico-causais (CASTRO, 2014, p. 27). O primeiro está voltado para compreensão dos conceitos espontâneos, enquanto o segundo, para compreensão dos conceitos científicos a partir dos espontâneos.

\section{REFERÊNCIAS}

BAHAR, M., JOHNSTONE, A., H.; HANSELL, M. H. Revisiting Learning Difficulties in Biology. Journal of Biological Education, Glasgow, n. 33, 84-87, 1999.

BOGDAN, R. C.; BIKLEN, S. K. A investigação qualitativa em educação: uma introdução à teoria e aos métodos. Portugal: Porto Editora, 1994.

CABALLER, M. J.; GIMÉNEZ, I. Las ideas del alumnado sobre el concepto de célula al finalizar la educación general básica. Enseñanza de las Ciencias, Barcelona, v. 11, n. 1, p. 63-68, 1993.

CASTRO, D. R. Estudo de Conceitos de Estrutura e Funcionalidade de Seres Vivos no Ensino Fundamental I. 2014. 341 f.. Tese (Doutorado em Ensino, Filosofia e História das Ciências) Universidade Federal da Bahia. Salvador, 2014.

. Estudo de Conceitos de Seres Vivos nas Séries Iniciais. 2010. 174f. Dissertação (Mestrado em Ensino, Filosofia e História das Ciências) - Universidade Federal da Bahia. Salvador, 2010.

GASPARIN, João Luiz. A construção dos conceitos científicos em sala de aula. 2007. Disponível em: <http://www.pesquisa.uncnet.br/pdf/palestra Conferencistas/A CONSTRUCAODOS CONCEITOS CIENTIFCOS EM SALA DE AULA.pdf>. Acesso em: 21 mar. 2009.

GÓMEZ, D. A. R. Propuesta didáctica para la enseñanza del concepto célula a partir de su historia y epistemología. 2011. 167f. Tese (Doutorado em Educación Ciencias Y Tecnología) - Universidad Del Vale. Santiago de Cali, Colombia, 2011.

JIMÉNEZ-ALEIXANDRE, M.P; DÍAZ-BUSTAMANTE, J. Drawing and slicing cells: In: THE PROCEEDINGS OF THE THIRD INTERNATIONAL SEMINAR ON MISCONCEPTIONS AND EDUCATIONAL STRATEGIES IN SCIENCE AND MATHEMATICS, 1993, Nova York. Anais... Nova York: Misconceptions Trust, 1993.

MILES, M. B.; HUBERMAN, A. M. Qualitative Data Analysis. $2^{\text {nd }}$ ed. London: SAGE Publications, 1994.

MOURA, M. P. Desenvolvimento do pensamento: um estudo sobre formação de conceitos com jovens e adultos em processo de escolarização. 2000. 157f. Dissertação (Mestrado em Psicologia Escolar e do Desenvolvimento Humano), Universidade de São Paulo. São Paulo, 2000.

SAVIANI, D. Escola e democracia. 37. ed. Campinas: Autores Associados, 2005. 
SFORNI, M.S.F. Aprendizagem conceitual e organização do ensino: contribuições da teoria da atividade. Araraquara: Junqueira \& Marin, 2004.

SHAEFER, G. Concept Formation in Biology: The Concept "Growth". European Journal of Science Education, California, v. 1, Issue 1, 1979.

TEKKAYA, C., OZKAN, O. AND SUNGUR, S. Biology Concepts Perceived as Difficult by Turkish High School Students. Journal of Hacettepe University Faculty of Education, Ankara, 21, p. 145-150, 2001.

TRIVIÑOS, A. N. S. Introdução à pesquisa em ciências sociais: a pesquisa qualitativa em educação. São Paulo: Atlas, 1987.

VYGOTSKY, L. S. A Construção do Pensamento e da Linguagem. 2. ed. São Paulo: Martins Fontes, 2010.

A Construção do Pensamento e da Linguagem. São Paulo: Martins Fontes, 2000.

Pensamento e linguagem. São Paulo: Martins Fontes, 1991.

Yorek, N., Sahin, M. \& Aydin, H. Are animals 'More Alive' than plants? Animistic-anthropocentric construction of life concept. Eurasia Journal of Mathematics, Science \& Technology Education, Ankara, v. 5, n. 4, p. 369-378, 2009.

YOREK, N.; SAHIN, M.; UGULU, I. Students' representations of the cell concept from 6 to11 grades: Persistence of the "fried-egg model". International Journal of Physical Sciences, Alsancak/İzmir, v. 5, n. 01, p. 15-24, jan. 2010. Disponível em: < http://www.academicjournals.org/ IJPS>. Acesso em: 20 mar. 2013.

ZAMORA, M. C.; SILVIA, E.; GUERRA, M. Misconceptions about cells: In: THE PROCEEDINGS OF THE THIRD INTERNATIONAL SEMINAR ON MISCONCEPTIONS AND EDUCATIONAL STRATEGIES IN SCIENCE AND MATHEMATICS, 1993, Nova York. Anais... Nova York: Misconceptions Trust, 1993.

Recebido: 23/11/2015

Aprovado: 25/07/2016

\section{Contato:}

Darcy Ribeiro de Castro

Rua Jutahy Magalhães Júnior, 41, Centro

Central-BA, CEP: 44:940.000 